\title{
Genetic and phenotypic heterogeneity in sporadic and familial forms of paroxysmal dyskinesia
}

\author{
Alexander J. A. Groffen · Thom Klapwijk • \\ Anne-Fleur van Rootselaar • Justus L. Groen • \\ Marina A. J. Tijssen
}

Received: 27 March 2012/Revised: 23 May 2012/ Accepted: 13 June 2012/Published online: 30 June 2012

(C) The Author(s) 2012. This article is published with open access at Springerlink.com

\begin{abstract}
Paroxysmal dyskinesia (PxD) is a group of movement disorders characterized by recurrent episodes of involuntary movements. Familial paroxysmal kinesigenic dyskinesia (PKD) is caused by PRRT2 mutations, but a distinct etiology has been suggested for sporadic PKD. Here we describe a cohort of patients collected from our movement disorders outpatient clinic in the period 1996-2011. Fifteen patients with sporadic PxD and 23 subjects from three pedigrees with familial PKD were screened for mutations in candidate genes. PRRT2 mutations co-segregated with PKD in two families and occurred in two sporadic cases of PKD. No mutations were detected in patients with non-kinesigenic or exertion-induced dyskinesia, and none in other candidate genes including PNKDI (MR-1) and SLC2Al (GLUT1). Thus, PRRT2 mutations also cause sporadic PKD as might be expected
\end{abstract}

A. J. A. Groffen and T. Klapwijk contributed equally.

Electronic supplementary material The online version of this article (doi:10.1007/s00415-012-6592-5) contains supplementary material, which is available to authorized users.

A. J. A. Groffen

Departments of Clinical Genetics and Functional Genomics,

Center of Neurogenomics and Cognitive Research (CNCR),

VU University and VU Medical Center, Amsterdam,

The Netherlands

e-mail: a.j.a.groffen@vu.nl

T. Klapwijk · A.-F. van Rootselaar · J. L. Groen

Department of Neurology, Academic Medical Center,

University of Amsterdam, Amsterdam, The Netherlands

\section{A. J. Tijssen ( $\square)$}

Department of Neurology AB 51, University Medical Center

Groningen, P.O. Box 30.001, 9700 RB Groningen,

The Netherlands

e-mail: m.a.j.de.koning-tijssen@umcg.nl given the variable expressivity and reduced penetrance observed in familial PKD. Further genetic heterogeneity is suggested by the absence of candidate gene mutations in both sporadic and familial PKD suggesting a contribution of other genes or non-coding regions.

Keywords Paroxysmal kinesigenic dyskinesia - Infantile convulsions and paroxysmal choreoathetosis $\cdot$ Benign familial neonatal convulsions · Migraine

\section{Introduction}

Paroxysmal dyskinesias (PxDs) are characterized by recurrent episodes of abnormal involuntary movements [1]. The movement disorder may clinically present as dystonia, chorea, ballism or a mixture of these [2]. Attacks often begin in childhood [3]. A classification scheme distinguishes four subtypes: paroxysmal kinesigenic (PKD), non-kinesigenic (PNKD), exertion-induced (PED) and hypnogenic dyskinesia (PND) [2].

In PKD, the most frequent form, attacks are precipitated by voluntary movements and usually last less than 5 min [4]. Familial PKD inherits in an autosomal dominant mode with reduced penetrance [3]. Infantile convulsions (IC) were frequently observed in the same pedigree and PKD and ICCA (IC with choreoathetosis) are now considered the same disorder [5-9]. Recently, the PRRT2 gene was shown to cause familial PKD [10-16]. A quarter of PKD cases are sporadic. Several observations suggested that sporadic and familial forms may be etiologically distinct, featuring a higher number of attacks per day and an increased co-occurrence of migraine in sporadic patients (full reference list in Online Resource 1).

In PNKD attacks are triggered by alcohol, caffeine, fatigue or excitement [2]. Attacks typically last minutes to $4 \mathrm{~h}$. 
Mutations in the $M R-1$ gene have been detected in several families $[17,18]$. Clonazepam or other benzodiazepines can be helpful in some $M R-1$ mutation carrier patients [19].

PED is triggered by prolonged physical exercise [20]. The symptom duration varies from 5-30 min $[1,3]$. Few families have been described [21-24] as well as some sporadic patients $[25,26]$. In some families epilepsy or migraine co-occur. In nine families with PED and epilepsy, mutations were found in the SLC2Al gene encoding the glucose transporter GLUT1 [27, 28].

Here we investigated a cohort of 33 Dutch PxD patients and found PRRT2 frameshift mutations in both familial and sporadic cases of PKD. Furthermore, the majority of sporadic PxD cases as well as one PKD family did not carry mutations in PRRT2, MR-1 or GLUT1, suggesting a contribution of additional genes or non-coding mutations.

\section{Subjects and methods}

This study was performed in accordance with the ethical standards laid down in the 1964 declaration of Helsinki and was approved by the Institutional Review Board of the VU Medical Center (\#2009/174). Informed written consent was obtained from all participating subjects. All patients with PxD in the Academic Medical Center (AMC), diagnosed between 1996 and 2010 were asked to participate. All participants completed a standardised questionnaire including age at onset, frequency, duration, triggers, symptoms during attacks, precipitating and alleviating factors, symptoms after an attack and family and medical history. Medical records EEG (electro-encephalogram, if achieved) and imaging reports were reviewed. In PKD families some unaffected family members were also examined. For genetic analysis, we collected venous blood samples (adults) or sputum (children). Genomic DNA was isolated using the PureGene Blood core kit (Qiagen). For familial cases, co-seggregation of the phenotype with chromosome 16 was confirmed using 23 microsatellite repeats (see Online Resource 2). PCR amplification of target genes was performed using primers specified in Online Resource 3. Products were sequenced using BigDyeTerminator v3.1 reagents and analyzed in a ABI Prism 3137 genetic analyzer. All patients were tested for PRRT2. Patients with PKD or PED were also tested for mutations in GLUT1. PNKD patients were also tested for $M R-1$ gene mutations.

\section{Results}

Patients

Thirty-three PxD patients were detected and 23 volunteered to participate. Sixteen patients met the criteria for
PKD including seven patients with a positive family history (Table 1 ). The average age at onset was 14.1 years (ranging from 0 to 51) and did not differ significantly between familial and sporadic cases (12.4 and 15.4 years, respectively). There is a male predominance $(63 \%)$. Dystonia was observed in $88 \%$ of the patients, whereas $31 \%$ exhibited chorea. Combined dystonia and chorea was observed in $25 \%$ of the patients. Seven patients tried carbamazepine and all experienced good control of complaints. Accompanying ailments were IC, epilepsy, migraine and tremor. It should be noted that IC were only present in the familial group.

The first family of Indonesian descent (Fig. 1) contains two patients with PKD, one with IC and one with migraine. The index patient (II-2), a 37-year-old woman, reported attacks of $10 \mathrm{~s}$ or less since the age of 12 years. Attacks consisted of a right-sided dystonic posture of her neck, jaw, hand, arm and leg. She experienced a preceding sensation and could abort attacks, the frequency of which decreased without medication. Her younger brother (III-3) had an identical phenotype. His attacks stopped with carbamazepine $(50 \mathrm{mg}$ per 2 days). Her daughter (IV-2) had IC without EEG abnormalities at the age of 6 months. In the past her mother (I-2) had migraine.

The second family consists of three PKD patients of Dutch origin. The index patient (IV-2), a 13-year-old boy had paroxysms since the age of 10 years after switching from rest to action. The attacks consisted of dystonic posture of his left arm followed by his mouth and leg. He had tremors of the hands and sudden involuntary movement of his neck. The patient experienced a preceding sensation and could abort an attack. The attacks presented less than five times a day, lasted $10-15 \mathrm{~s}$ and ceased with carbamazepine (50 $\mathrm{mg}$ dd). His mother (III-1) experienced similar attacks in her youth (10-20 years). She also reported a febrile convulsion at 1 year of age. The grandfather (II-4) had similar attacks when he was young and also exhibited tremors of the hands. A great-uncle (II-1) also experienced involuntary movements, but specifics were not possible to collect. The older brother (IV-1) had a febrile convulsion at 1 year of age.

The third family includes two PKD patients. The index patient (III-1) had PKD since age 15 years. The attack consisted of left-sided slow kicking movements causing him to fall. Occasionally a sensory warning preceded the attack, but he was unable to prevent attacks. They stopped with carbamazepine ( $2 \mathrm{dd} 200 \mathrm{mg}$ ). He was previously diagnosed with benign familial infantile convulsions (BFIC) treated with valproic acid, and had a single generalized tonic-clonic seizure at age 13 years and twice again at age 14 years. Interictal EEG showed series of epileptic discharges over the right frontocentral area, especially during drowsiness and hyperventilation [29]. Considering the PKD and seizures, the diagnosis ICCA was made. 


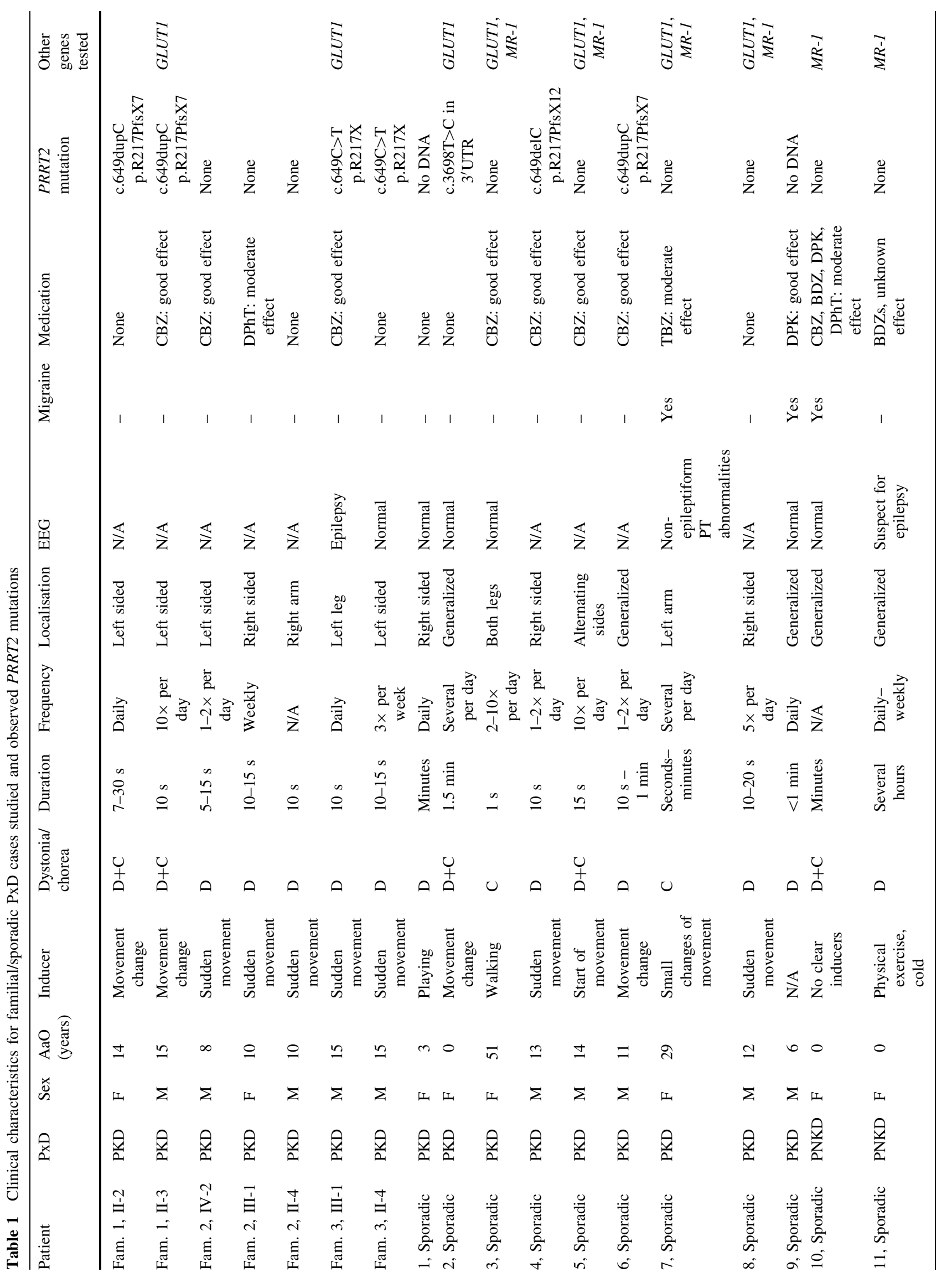




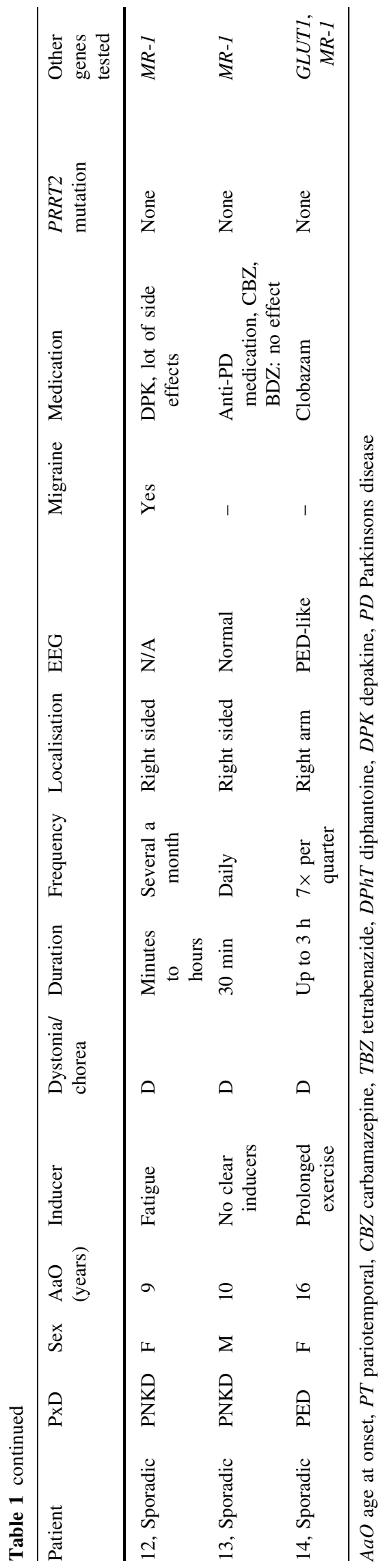

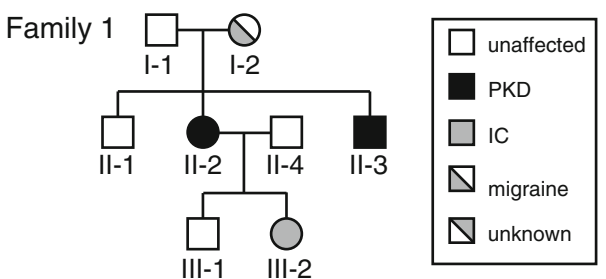
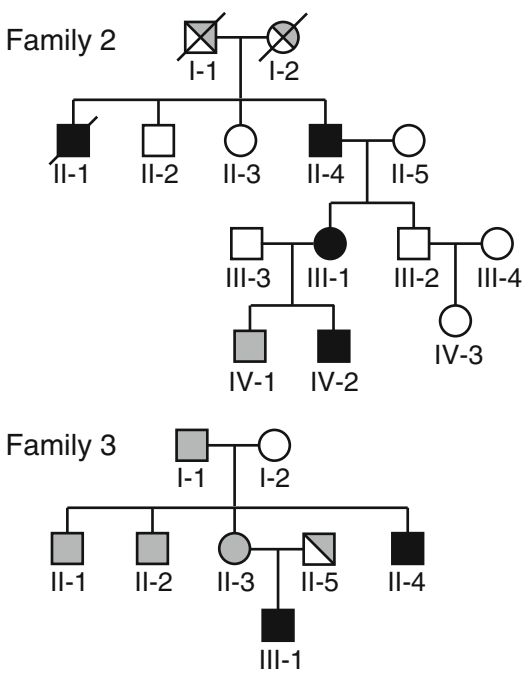

Fig. 1 Pedigrees with familial PKD. Convulsions co-occurred in all families

Besides PKD patients, our cohort contained four sporadic PNKD patients and one female PED patient. The average onset age of PNKD was $4.75(0-10)$ years similar to previous findings $[1,26,30]$. Again, dystonia was the most common expression. Two patients tried carbamazepine without effect. Two patients had migraine. The female PED patient had isolated dystonia. Complaints started at age 16 years; attacks gradually decreased and she had her last attack at age 23 years. During an attack she took clobazam to stop the complaints. It is common to have no family history for PED [26].

Several patients underwent a brain CT-scan or MRI (Table 1). All were normal. Only in the PED patient three small lacunar lesions appeared in the right sided basal ganglia, especially the global pallidus and adjacent to the internal capsule. In EEG registrations, most of the patients showed no epileptic discharges. Clinical epilepsy was confirmed by neurophysiological investigation in only one PKD patient (III-1 of family 3) (Table 1). In a patient with PNKD and mental retardation an EEG showed indications for epilepsy, but clinically no convulsions ever occurred.

\section{Mutation detection}

For familial PKD, PRRT2 mutations have been observed in multiple Han Chinese families [10-13, 16, 31]. Consistently, we observed PRRT2 mutations in family 1 

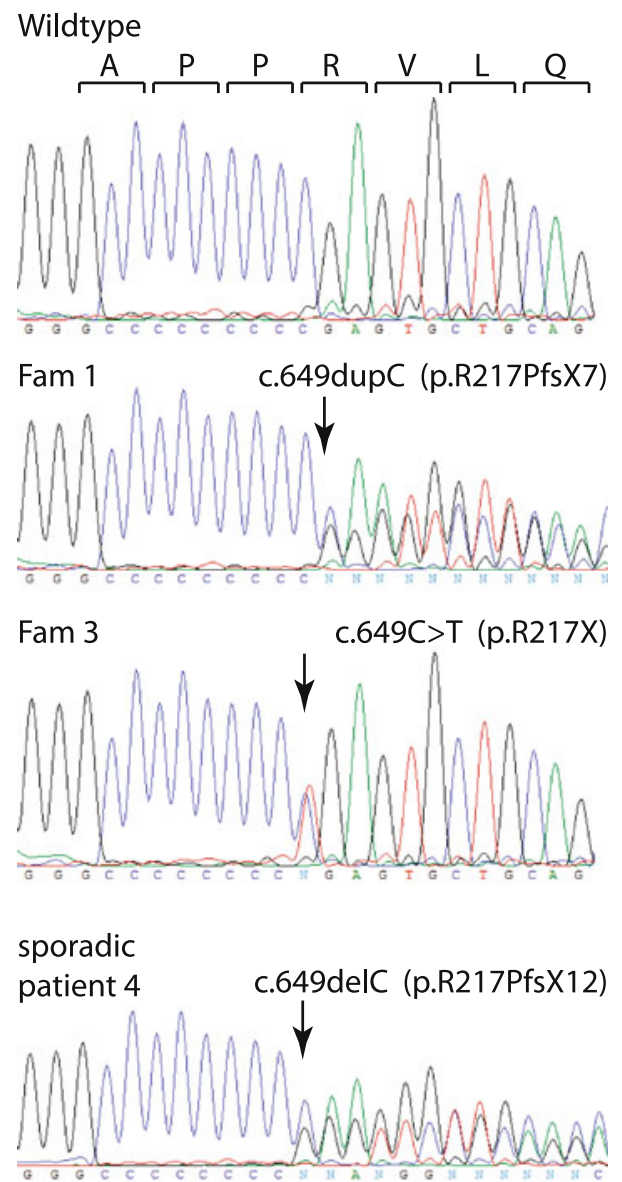

sporadic

patient 6

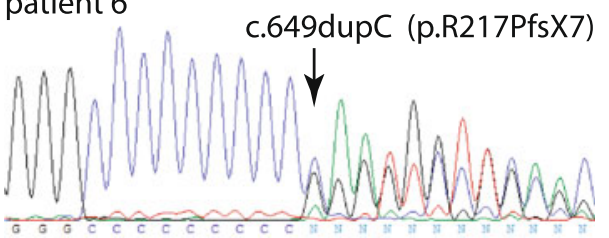

Fig. 2 Sequence traces of observed PRRT2 mutations. Top trace indicates the wildtype sequence and the corresponding open reading frame. Arrows indicate mutated residues

(c.649dupC) and 3 (c.649C $>\mathrm{T}$, introducing an opal stop codon replacing proline 217). In family 2 we did not find any mutation, although the phenotype co-seggregated with a region of chromosome 16p distal from marker D16S685 (see Online Resource 2).

In addition, two sporadic PKD patients carried frameshift mutations in PRRT2 (Table 1; Fig. 2) c.649delC (patient 4) and c.649dupC (patient 6). Another variation, c.3698T $>C$, was observed in the $3^{\prime}$ UTR in exon 4. Although this variation is not reported in dbSNP or the 1,000 genome database it is not predicted to have major effects on PRRT2 gene function.

Six out of nine cases of sporadic PKD were not associated with mutations in PRRT2. We also did not detect mutations in other candidate genes tested including $M R-1$ (known to cause PNKD) and GLUTl (known to cause PED and sporadic PKD) [32].

\section{Discussion}

We investigated the clinical and genetic aspects of $21 \mathrm{PxD}$ patients seen over the last 15 years in our third opinion movement disorder out-patient clinic. This cohort comprised 16 patients with PKD, four with PNKD and one with PED. Familial PKD co-seggregated with the known locus in all pedigrees. PRRT2 truncating mutations were identified in two families and two sporadic cases.

In our study $53 \%$ of the PKD patients were sporadic cases, whereas only $4.8 \%$ of published cases were sporadic $[4,33]$. Possibly sporadic forms are underrepresented, because linkage and gene identification studies preferentially focussed on familial forms. Other clinical aspects of patients in our cohort were similar to those of in total 681 published PKD patients (see Online Resource 1). The mean age at onset was similar (10.4 years on average) and as in our cohort, dystonia was also the most common movement disorder in literature (seen in $43 \%$ of patients). Both in literature (30\%) and in our findings PKD and IC are correlated, especially in the familial forms [9].

The clinical features of sporadic and familial PKD patients were similar, although IC were observed only in the familial group. Migraine occurred in two of nine sporadic PKD cases and in one PRRT2 mutation carrier in family 1 (I-2). The attacks were preceded by an aura in $93 \%$ of sporadic patients and in all adult familial patients questioned.

Despite the previous idea that sporadic and familial PKD represent distinct diseases, we observed identical mutations in sporadic and familial PKD [11-13]. This is consistent with a recent study [16]. A pseudo-sporadic occurrence is not surprising in view of the reduced penetrance of familial PKD combined with the variable clinical expression that includes IC, BFIC and migraine [14, 15].

The lack of PRRT2 mutations in four out of seven sporadic cases from our cohort suggests that additional PKD genes exist. In another recent study, seven out of eight sporadic cases were negative for PRRT2 mutations [16]. Similarly, familial PKD cases occur without PRRT2 mutations both in our study and previous investigations [16]. This suggests a contribution of other genes which may co-segregate with the same locus as $P R R T 2$ or alternatively of non-coding mutations that may affect $P R R T 2$ gene function.

Acknowledgments We are grateful to patients and families who participated in the study. Zabiollah Abbas is acknowledged for expert 
technical assistance. This work was supported by the Prinses Beatrix Foundation (WAR08-07 to Groffen). Tijssen received support from the Prinses Beatrix Foundation, STW Technology society program: Perspective-NeuroSIPE the ONWA Graduate School of Neurosciences Amsterdam and Ipsen Farmaceutics. Groen received an AMC Graduate School Scholarship.

\section{Conflicts of interest None.}

Open Access This article is distributed under the terms of the Creative Commons Attribution License which permits any use, distribution, and reproduction in any medium, provided the original author(s) and the source are credited.

\section{References}

1. Bhatia KP (2001) Familial (idiopathic) paroxysmal dyskinesias: an update. Semin Neurol 21:69-74

2. Demirkiran M, Jankovic J (1995) Paroxysmal dyskinesias: clinical features and classification. Ann Neurol 38:571-579

3. Mink JW (2007) Paroxysmal dyskinesias. Curr Opin Pediatr 19: 652-656

4. Bruno MK, Hallett M, Gwinn-Hardy K, Sorensen B, Considine E, Tucker S, Lynch DR, Mathews KD, Swoboda KJ, Harris J, Soong BW, Ashizawa T, Jankovic J, Renner D, Fu YH, Ptacek LJ (2004) Clinical evaluation of idiopathic paroxysmal kinesigenic dyskinesia: new diagnostic criteria. Neurology 63:2280-2287

5. Lee WL, Tay A, Ong HT, Goh LM, Monaco AP, Szepetowski P (1998) Association of infantile convulsions with paroxysmal dyskinesias (ICCA syndrome): confirmation of linkage to human chromosome 16p12-q12 in a Chinese family. Hum Genet 103: 608-612

6. Rochette J, Roll P, Fu YH, Lemoing AG, Royer B, Roubertie A, Berquin P, Motte J, Wong SW, Hunter A, Robaglia-Schlupp A, Ptacek LJ, Szepetowski P (2010) Novel familial cases of ICCA (infantile convulsions with paroxysmal choreoathetosis) syndrome. Epileptic Disord 12:199-204

7. Roll P, Sanlaville D, Cillario J, Labalme A, Bruneau N, Massacrier A, Delepine M, Dessen P, Lazar V, Robaglia-Schlupp A, Lesca G, Jouve E, Rudolf G, Rochette J, Lathrop GM, Szepetowski P (2010) Infantile convulsions with paroxysmal dyskinesia (ICCA syndrome) and copy number variation at human chromosome 16p11. PLoS One 5:e13750

8. Swoboda KJ, Soong B, McKenna C, Brunt ER, Litt M, Bale JF Jr, Ashizawa T, Bennett LB, Bowcock AM, Roach ES, Gerson D, Matsuura T, Heydemann PT, Nespeca MP, Jankovic J, Leppert M, Ptacek LJ (2000) Paroxysmal kinesigenic dyskinesia and infantile convulsions: clinical and linkage studies. Neurology 55:224-230

9. Szepetowski P, Rochette J, Berquin P, Piussan C, Lathrop GM, Monaco AP (1997) Familial infantile convulsions and paroxysmal choreoathetosis: a new neurological syndrome linked to the pericentromeric region of human chromosome 16. Am J Hum Genet 61:889-898

10. Lee HY, Huang Y, Bruneau N, Roll P, Robertson EDO, Hermann M, Quinn E, Maas J, Edwards R, Ashizawa T, Ptacek LJ (2012) Mutations in the gene PRRT2 cause paroxysmal kinesigenic dyskinesia with infantile convulsions. Cell Reports 1(1):2-12

11. Wang JL, Cao L, Li XH, Hu ZM, Li JD, Zhang JG, Liang Y, San A, Li N, Chen SQ, Guo JF, Jiang H, Shen L, Zheng L, Mao X, Yan WQ, Zhou Y, Shi YT, Ai SX, Dai MZ, Zhang P, Xia K,
Chen SD, Tang BS (2011) Identification of PRRT2 as the causative gene of paroxysmal kinesigenic dyskinesias. Brain 134: 3490-3498

12. Li J, Zhu X, Wang X, Sun W, Feng B, Du T, Sun B, Niu F, Wei H, Wu X, Dong L, Li L, Cai X, Wang Y, Liu Y (2011) Targeted genomic sequencing identifies PRRT2 mutations as a cause of paroxysmal kinesigenic choreoathetosis. J Med Genet 49(2): 76-78

13. Chen WJ, Lin Y, Xiong ZQ, Wei W, Ni W, Tan GH, Guo SL, He J, Chen YF, Zhang QJ, Li HF, Murong SX, Xu J, Wang N, Wu ZY (2011) Exome sequencing identifies truncating mutations in PRRT2 that cause paroxysmal kinesigenic dyskinesia. Nat Genet 43:1252-1255

14. Ono S, Yoshiura KI, Kinoshita A, Kikuchi T, Nakane Y, Kato N, Sadamatsu M, Konishi T, Nagamitsu S, Matsuura M, Yasuda A, Komine M, Kanai K, Inoue T, Osamura T, Saito K, Hirose S, Koide H, Tomita H, Ozawa H, Niikawa N, Kurotaki N (2012) Mutations in PRRT2 responsible for paroxysmal kinesigenic dyskinesias also cause benign familial infantile convulsions. J Hum Genet 57(5):338-341

15. Heron SE, Grinton BE, Kivity S, Afawi Z, Zuberi SM, Hughes JN, Pridmore C, Hodgson BL, Iona X, Sadleir LG, Pelekanos J, Herlenius E, Goldberg-Stern H, Bassan H, Haan E, Korczyn AD, Gardner AE, Corbett MA, Gecz J, Thomas PQ, Mulley JC, Berkovic SF, Scheffer IE, Dibbens LM (2012) PRRT2 mutations cause benign familial infantile epilepsy and infantile convulsions with choreoathetosis syndrome. Am J Hum Genet 90:152-160

16. Cao L, Huang XJ, Zheng L, Xiao Q, Wang XJ, Chen SD (2012) Identification of a novel PRRT2 mutation in patients with paroxysmal kinesigenic dyskinesias and c.649dupC as a mutation hot-spot. Parkinsonism Relat Disord 18(5):704-706

17. Lee HY, Xu Y, Huang Y, Ahn AH, Auburger GW, Pandolfo M, Kwiecinski H, Grimes DA, Lang AE, Nielsen JE, Averyanov Y, Servidei S, Friedman A, Van Bogaert P, Abramowicz MJ, Bruno MK, Sorensen BF, Tang L, Fu YH, Ptacek LJ (2004) The gene for paroxysmal non-kinesigenic dyskinesia encodes an enzyme in a stress response pathway. Hum Mol Genet 13:3161-3170

18. Rainier S, Thomas D, Tokarz D, Ming L, Bui M, Plein E, Zhao X, Lemons R, Albin R, Delaney C, Alvarado D, Fink JK (2004) Myofibrillogenesis regulator 1 gene mutations cause paroxysmal dystonic choreoathetosis. Arch Neurol 61:1025-1029

19. Bruno MK, Lee HY, Auburger GW, Friedman A, Nielsen JE, Lang AE, Bertini E, Van Bogaert P, Averyanov Y, Hallett M, Gwinn-Hardy K, Sorenson B, Pandolfo M, Kwiecinski H, Servidei S, Fu YH, Ptacek L (2007) Genotype-phenotype correlation of paroxysmal nonkinesigenic dyskinesia. Neurology 68:1782-1789

20. Lance JW (1977) Familial paroxysmal dystonic choreoathetosis and its differentiation from related syndromes. Ann Neurol 2: 285-293

21. Guerrini R, Bonanni P, Nardocci N, Parmeggiani L, Piccirilli M, De Fusco M, Aridon P, Ballabio A, Carrozzo R, Casari G (1999) Autosomal recessive rolandic epilepsy with paroxysmal exerciseinduced dystonia and writer's cramp: delineation of the syndrome and gene mapping to chromosome 16p12-11.2. Ann Neurol 45: 344-352

22. Munchau A, Valente EM, Shahidi GA, Eunson LH, Hanna MG, Quinn NP, Schapira AH, Wood NW, Bhatia KP (2000) A new family with paroxysmal exercise induced dystonia and migraine: a clinical and genetic study. J Neurol Neurosurg Psychiatry 68: 609-614

23. Perniola T, Margari L, de Iaco MG, Presicci A, Ventura P, Ferrannini E, Illiceto G (2001) Familial paroxysmal exerciseinduced dyskinesia, epilepsy, and mental retardation in a family 
with autosomal dominant inheritance. Mov Disord 16:724-730

24. Kamm C, Mayer P, Sharma M, Niemann G, Gasser T (2007) New family with paroxysmal exercise-induced dystonia and epilepsy. Mov Disord 22:873-877

25. Bakker MJ, van Dijk JG, van den Maagdenberg AM, Tijssen MA (2006) Startle syndromes. Lancet Neurol 5:513-524

26. Bhatia KP, Soland VL, Bhatt MH, Quinn NP, Marsden CD (1997) Paroxysmal exercise-induced dystonia: eight new sporadic cases and a review of the literature. Mov Disord 12:1007-1012

27. Suls A, Dedeken P, Goffin K, Van Esch H, Dupont P, Cassiman D, Kempfle J, Wuttke TV, Weber Y, Lerche H, Afawi Z, Vandenberghe W, Korczyn AD, Berkovic SF, Ekstein D, Kivity S, Ryvlin P, Claes LR, Deprez L, Maljevic S, Vargas A, Van Dyck T, Goossens D, Del-Favero J, Van Laere K, De Jonghe P, Van Paesschen W (2008) Paroxysmal exercise-induced dyskinesia and epilepsy is due to mutations in SLC2A1, encoding the glucose transporter GLUT1. Brain 131:1831-1844

28. Weber YG, Storch A, Wuttke TV, Brockmann K, Kempfle J, Maljevic S, Margari L, Kamm C, Schneider SA, Huber SM, Pekrun A, Roebling R, Seebohm G, Koka S, Lang C, Kraft E, Blazevic D, Salvo-Vargas A, Fauler M, Mottaghy FM, Munchau A, Edwards MJ, Presicci A, Margari F, Gasser T, Lang F, Bhatia
KP, Lehmann-Horn F, Lerche H (2008) GLUT1 mutations are a cause of paroxysmal exertion-induced dyskinesias and induce hemolytic anemia by a cation leak. J Clin Invest 118:2157-2168

29. Van Strien TW, Van Rootselaar AF, Hilgevoord AA, Linssen WH, Groffen AJ, Tijssen MA (2012) Paroxysmal kinesigenic dyskinesia: Cortical or non-cortical origin. Parkinsonism Relat Disord 18:645-648

30. Plant GT, Williams AC, Earl CJ, Marsden CD (1984) Familial paroxysmal dystonia induced by exercise. J Neurol Neurosurg Psychiatry 47:275-279

31. Liu Q, Qi Z, Wan XH, Li JY, Shi L, Lu Q, Zhou XQ, Qiao L, Wu LW, Liu XQ, Yang W, Liu Y, Cui LY, Zhang X (2012) Mutations in PRRT2 result in paroxysmal dyskinesias with marked variability in clinical expression. J Med Genet 49:79-82

32. Schneider SA, Paisan-Ruiz C, Garcia-Gorostiaga I, Quinn NP, Weber YG, Lerche H, Hardy J, Bhatia KP (2009) GLUT1 gene mutations cause sporadic paroxysmal exercise-induced dyskinesias. Mov Disord 24:1684-1688

33. Hattori H, Fujii T, Nigami H, Higuchi Y, Tsuji M, Hamada Y (2000) Co-segregation of benign infantile convulsions and paroxysmal kinesigenic choreoathetosis. Brain Dev 22:432-435 